\title{
CORRIGENDUM
}

\section{Electrochemical coupling in the voltage-dependent phosphatase Ci-VSP}

Susy C Kohout, Sarah C Bell, Lijun Liu, Qiang Xu, Daniel L Minor Jr \& Ehud Y Isacoff

Nat. Chem. Biol. 6, 369-375 (2010); published online 4 April 2010; corrected after print 17 September 2010

After publication, the authors found second-site mutations within two of the Ci-VSP constructs. The R253Q G214C and R254Q G214C constructs have been remade without the additional mutations and the data recollected. The data originally presented in Figure 1, Supplementary Figures 5 and 6 and Supplementary Table 1 have been updated to reflect the minor changes in the magnitude of the constructs' effects. The changes do not affect the conclusions of the study. The changes have been made in the HTML and PDF versions of the article.

\section{ERRATUM}

\section{$A B C$ proteins in antigen translocation and viral inhibition}

David Parcej \& Robert Tampé

Nat. Chem. Biol. 6, 572-580 (2010); published online 19 July 2010; corrected after print 17 September 2010

In the version of this article initially published, four of the ATP molecules in Figure 4a were incorrectly labeled as ADP. The errors have been corrected in the HTML and PDF versions of the article. 